\title{
Cutoff points of BMI for classification of nutritional status using bioelectrical impedance analysis
}

\author{
Mirele S. Mialich ${ }^{1}$, Bruna R. Silva ${ }^{1}$ and Alceu A. Jordao ${ }^{1}$ \\ 1. Department of Internal Medicine, Ribeirao Preto Medical School, University of Sao Paulo. Ribeirao Preto, SP, Brazil. \\ 2. E-mail any correspondence to: mirelemialich@yahoo.com.br
}

\begin{abstract}
The objective of this study was to improve the cutoff points of the traditional classification of nutritional status and overweight / obesity based on the BMI in a Brazilian sample. A cross-sectional study was conducted on 1301 individuals of both genders aged 18 to 60 years. The subjects underwent measurement of weight and height and bioelectrical impedance analysis. Simple linear regression was used for statistical analysis, with the level of significance set at $p<0.05$. The sample consisted of $29.7 \%$ men and $70.3 \%$ women aged on averaged $35.7 \pm 17.6$ years; mean weight was $67.6 \pm 16.0 \mathrm{~kg}$, mean height was $164.9 \pm 9.5 \mathrm{~cm}$, and mean BMI was $24.9 \pm 5.5 \mathrm{~kg} / \mathrm{m}^{2}$. As expected, lower cutoffs were found for BMI than the classic reference points traditionally adopted by the WHO for the classification of obesity, i.e., 27.15 and $27.02 \mathrm{~kg} / \mathrm{m}^{2}$ for obesity for men and women, respectively. Other authors also follow this tendency, Romero-Corral et al. (2008) suggested 25.8 to $25.5 \mathrm{~kg} / \mathrm{m}^{2}$ for American men and women as new values for BMI classification of obesity. Gupta and Kapoor (2012) proposed 22.9 and $28.8 \mathrm{~kg} / \mathrm{m}^{2}$ for men and women of North India. The present investigation supports other literature studies which converge in reducing the BMI cutoff points for the classification of obesity. Thus, we emphasize the need to conduct similar studies for the purpose of defining these new in populations of different ethnicities.
\end{abstract}

Keywords: Body mass index; cutoff points; body fat; obesity; bioelectrical impedance

\section{Introduction}

The prevalence of overweight and obesity is increasing at an alarming rate in developed and developing countries the world over [1,2]. Epidemiological studies indicate that overweight and obesity are important risk factors for diabetes, cardiovascular disease, cancer and premature death [2]. Thus, this increased prevalence, in combination with the concomitant health risks, becomes a particularly relevant worldwide public health challenge [3].

This increased prevalence of excess weight/obesity has been reported in various world regions and, in view of its growing importance for public health, precise estimates of the global load of this condition are crucial for the elaboration of public health strategies directed at its primary prevention and treatment [3].

According to the World Health Organization (WHO), obesity is defined as excess adipose tissue [4] and, in view of its increasing incidence, it is considered a worldwide epidemic affecting both developed and developing countries [5].

The WHO projected that by 2005 the world would have 1.6 billion people older than 15 years with excess weight $\left(\mathrm{BMI} \geq 25.0 \mathrm{~kg} / \mathrm{m}^{2}\right.$ ) and 400 million people with obesity $\left(\mathrm{BMI} \geq 30.0 \mathrm{~kg} / \mathrm{m}^{2}\right)$. The projection for 2015 was even more pessimistic, i.e., 2.3 billion people with excess weight and 700 million obese people, indicating a $75 \%$ increase in cases of obesity within 10 years, with Brazil occupying $77^{\text {th }}$ position in the WHO ranking [6].

The index universally accepted for the diagnosis and classification of obesity is the BMI, which is expressed by subject weight in $\mathrm{kg}$ divided by squared height in meters (weight/height ${ }^{2}$ ) [7]. In 1997, the WHO adopted this index as reference for the measurement of obesity, with overweight being defined as a BMI range of 25.0-29.9 
$\mathrm{kg} / \mathrm{m}^{2}$ and obesity as a BMI above $30.0 \mathrm{~kg} / \mathrm{m}^{2}$ [8]. These values were obtained based on the associations between $\mathrm{BMI}$ and mortality in European populations, which formed a $\mathrm{J}$ curve between the values of 18.5 and $25.0 \mathrm{~kg} / \mathrm{m}^{2}$ [9]. Since then, these cutoff points have been used as standard for different populations and different ethnic groups based on the assumption that these different ethnic groups have a similar mortality/morbitity risk.

Recently, a new entity called normal weight obesity (NWO) was created, representing a condition in which an individual has an adequate BMI but an increased percentage of body fat and a higher risk of developing chronic diseases [10]. Although the investigations are recent, it has been estimated that about 30 million Americans are affected by NWO [11,12]. However, this prevalence has not been well established and there is wide variation among the studies conducted thus far, attributed to aspects such as ethnic differences, diverse methods used to assess body composition and different cutoff points established for a diagnosis of NWO.

In this respect, recent studies [13-15] have demonstrated that when the traditional BMI is considered, there still is controversy about the best BMI for the classification of obesity in different populations. In addition, recent evidence suggests that the relation between increased BMI and percent body fat also differs among various ethnic groups.

Thus, in view of this tendency, the objective of the present study was to propose a refinement of the reference points of the traditional BMI for the classification of nutritional status, especially overweight/obesity, in a sample of the Brazilian population, and to discuss the new proposed cutoff points for the BMI described in the literature in order to favor an earlier clinical intervention with the consequence of reduction of healthcare costs.

\section{Materials and methods}

\section{Subjects}

The study was conducted on healthy subjects of both genders, i.e., adolescents aged 17 years to 19 years and adults aged 20 years or older [8], who were students, employees, patients and/or accompanying persons of USP or of the University Hospital of Ribeirão Preto. Women of fertile age were asked to provide information about their menstrual cycle in view of the possibility that changes in water balance might interfere with the results of bioelectrical impedance. Exclusion criteria were: Persons younger than 17 years, unable to walk, amputated, with water retention or having metal objects in their body that might interfere with the results of bioelectrical impedance.

\section{Data Collection}

All subjects in the final sample $(n=1301)$ were submitted to measurement of weight and height so that the reference points of the BMI could be refined for the detection of overweight/obesity. On a previously scheduled visit, the subjects received a Free and Informed Consent Term (Protocol no 1955/2010) and only after they accepted and signed it, they were weighed on a BC-558 Ironman Segmental Body Composition Monitor electronic scale (Tanita Corp., Tokyo, Japan). This is a tetrapolar equipment that performs unifrequency analyses and the measured values are: Total and segmental body fat percentage, body water, total and segmental muscle mass, physique rating, bone mass, visceral fat rating with healthy range, basal metabolic rate (BMR) and metabolic age. The apparatus has a maximum capacity of $150 \mathrm{~kg}$ and a precision of $0.01 \mathrm{~kg}$.

Height was measured with a 2-meter portable anthropometer with $0.1 \mathrm{~cm}$ precision (a maximum variation of $0.5 \mathrm{~cm}$ was permitted between two measurements and the mean value was calculated). The subjects were evaluated in triplicate on only one occasion during the study by a group of trained examiners and the mean of the measurements obtained was calculated.

For the body composition exam, the subjects were instructed to wear light clothing and no socks and care was taken to verify that their heels were correctly aligned with the electrodes of the measuring platform. Next, the subjects held retractable levers with electrodes from which electric signals were emitted, traveling through the body.

The subjects were instructed to come after a fast of at least 5 hours, to avoid vigorous physical activity during the last 12 hours, to abstain from alcoholic or caffeinecontaining beverages 24 hours before the exam, to wear light clothing, and to urinate 30 minutes before the beginning of the exams. All metal objects were removed and the measurements were made after a 10-minute rest in the supine position in an air-conditioned room with a constant temperature of $20^{\circ} \mathrm{C}$.

\section{Statistical Analysis}

Simple linear regression analysis was used in order to define the new cutoff points of the BMI for the classification of obesity. The results are expressed as mean and standard deviation. Comparisons between two means were performed by the Student $t$-test and comparison betwee three means or more were performed by analysis of variance (ANOVA). All analyses were carried out with the aid of the SAS software version 9, with the level of significance set at $\mathrm{p}<0.05$.

\section{Results}

The study was conducted on 1301 volunteers, 386 (29.7\%) of them men and 915 (70.3\%) women. Mean age was $3.5 \pm 17.6$ years for men and $35.4 \pm 17.6$ years for women $(p=0.3033)$ and mean weight was $75.8 \pm 15.9 \mathrm{~kg}$ for men and $64.2 \pm 14.8 \mathrm{~kg}$ for women $(p<0.0001)$. Mean height was $173.9 \pm 8.2 \mathrm{~cm}$ for men and $161.1 \pm 7.1 \mathrm{~cm}$ for women 
( $p<0.0001$ ). Mean BMI was $24.9 \pm 5.5 \mathrm{~kg} / \mathrm{m}^{2}$ for all subjects as a whole and $25.0 \pm 4.6 \mathrm{~kg} / \mathrm{m}^{2}$ for men and $24.8 \pm 5.8 \mathrm{~kg} / \mathrm{m}^{2}$ for women $(p=0.5471)$.

The following bioelectrical impedance results were obtained: mean total fat mass (\%) $27.6 \pm 10.0 \%$, fat-free mass $(\mathrm{kg}) 45.8 \pm 10.2$, and total body water (\%) 52.8 \pm 7.5 . According to these data, the statistical differences between genders were $p<0.0001$ for total fat mass, $p<0.0001$ for fatfree mass, and $p<0.0001$ for total body water.

Figure 1 illustrates subject distribution separated by gender according to the classification ranges of the $\mathrm{BMI}$ suggested by the WHO [4]. A small percentage of students was found to be in the undernutrition range (BMI $<18.5$ $\left.\mathrm{kg} / \mathrm{m}^{2}\right)$, which was slightly more elevated in men $(7.7 \%)$ than in women (7.4\%). Most of the subjects of both genders were of normal weight (BMI of 18.5 to $24.9 \mathrm{~kg} / \mathrm{m}^{2}$ ), with values of $45.0 \%$ and $53.5 \%$ for men and women, respectively. On the basis of the $\mathrm{BMI}$ values that characterize excess weight, $32.6 \%$ of the men and $22.3 \%$ of the women were overweight ( $\geq 25.0$ and $<29.9 \mathrm{~kg} / \mathrm{m}^{2}$ ), $12.2 \%$ of the men and $9.9 \%$ of the women were in the range of grade I obesity (BMI of 30.0 to $34.9 \mathrm{~kg} / \mathrm{m}^{2}$ ), and a minority had grade II obesity (BMI of 35.0 and $39.9 \mathrm{~kg} / \mathrm{m}^{2}$ ) and grade III obesity $\left(\geq 40.0 \mathrm{~kg} / \mathrm{m}^{2}\right)$, with values of $1.8 \%$ and $0.5 \%$ for men and $4.3 \%$ and $2.5 \%$ for women, respectively.

Table 2 lists the distribution of the subjects within each BMI category and also according to the body fat ranges (\%) suggested by Gallagher et al. (2000) for the 20-39 year age range for a joint African American and Caucasian sample that was closest to the predominant sample of the present study considering the mean age of both genders [16]. It was possible to observe that only $52.3 \%$ (3.1\%. $29.3 \%$. $10.1 \%$ and $9.8 \%$ ) of men and $68.4 \%$ (4.9\%. 39.9\%. $10.5 \%$ and $13.1 \%$ ) of women were properly categorized by the BMI. Also according to BMI classification, $47.1 \%$ of men and $39.0 \%$ of women had excess weight (BMI of 25 to 29.9 $\mathrm{kg} / \mathrm{m}^{2}$ and above $30.0 \mathrm{~kg} / \mathrm{m}^{2}$.

Table 3 is a comparative presentation of the main studies cited above and their respective proposals of specific cutoff points according to ethnicity and/or gender. However, previous studies by our group conducted on smaller samples have already suggested the adoption of lower BMI cutoff points for the classification of obesity, i.e., $26.11 \mathrm{~kg} / \mathrm{m}^{2}$ for men and $25.3 \mathrm{~kg} / \mathrm{m}^{2}$ for women in a sample of 100 subjects [13]. In a later study conducted on 501 participants, the cut-off points detected for the BMI were: $22.67 \mathrm{~kg} / \mathrm{m}^{2}$ (for body fat $=30 \%$ ) and $25.24 \mathrm{~kg} / \mathrm{m}^{2}$ (for body fat $=35 \%$ ), both for women; $25.33 \mathrm{~kg} / \mathrm{m}^{2}$ (for body fat = $20 \%$ ) and $28.38 \mathrm{~kg} / \mathrm{m}^{2}$ (for body fat $=25 \%$ ), both for men, for the classification of overweight and obesity, respectively, since there is a tendency to also reduce these body fat values to $20 \%$ for men and $30 \%$ for women in order to include a larger number of individuals and to permit an earlier intervention [17].
In the present study, which involved a larger sample size, the expectation was to maintain this tendency to a reduction of $\mathrm{BMI}$ values for the classification of obesity, also observed as a global tendency according to studies by other research groups. In addition, this larger sample ( $n=1301$ ) is certainly more representative of the profile of the Brazilian population. On this basis, as shown in Figure 2, the final cutoff poins for the BMI suggested for the classification of excess weight in the present sample of the Brazilian population were $24.27 \mathrm{~kg} / \mathrm{m}^{2}$ (for body fat = 30\%) and $27.02 \mathrm{~kg} / \mathrm{m}^{2}$ (for body fat $=35 \%$ ), both for women; $25.24 \mathrm{~kg} / \mathrm{m}^{2}$ (for body fat $=20 \%$ ) and $27.15 \mathrm{~kg} / \mathrm{m}^{2}$ (for body fat $=25 \%)$, both fr men, for the classification of overweight and obesity, respectively (Figure 2).

Figure 3 illustrates the different percentages of subjects to be classified as having excess weight (obesity) according to different criteria. Thus, if we adopt the cutoff point traditionally proposed for the BMI (more than $30 \mathrm{~kg} / \mathrm{m}^{2}$ ), $14.5 \%$ and $16.7 \%$ of men and women, respcetively, are classified as obese. In contrast, using fat mass as reference ( $25 \%$ for men and $35 \%$ for women), the percentage of subjects to be included in this classification increases to $24.8 \%$ and $33.6 \%$ of men and women, respectively. Finally, when the new ranges for the classification of excess weight according to the BMI are adopted $\left(27.15 \mathrm{~kg} / \mathrm{m}^{2}\right.$ for men and $27.02 \mathrm{~kg} / \mathrm{m}^{2}$ for women), the number of subjects included becomes $28.7 \%$ for both genders in the sample studied here.

Table 1: Anthropometric and body composition characterization of the study sample.

\begin{tabular}{ccccc}
\hline Variable & Total & Males & Females & P value \\
\hline N & 1301 & 386 & 915 & 0.3033 \\
Age (years) & $35.7 \pm 17.6$ & $36.5 \pm 17.6$ & $35.4 \pm 17.6$ & $<0.0001^{*}$ \\
Weight (kg) & $67.6 \pm 16.0$ & $75.8 \pm 15.9$ & $64.2 \pm 14.8$ & $<0.0001^{*}$ \\
Height (cm) & $164.9 \pm 9.5$ & $173.9 \pm 8.2$ & $161.1 \pm 7.1$ & 0.5471 \\
BMI (kg/m $\left.{ }^{2}\right)$ & $24.9 \pm 5.5$ & $25.0 \pm 4.6$ & $24.8 \pm 5.8$ & $<0.0001^{*}$ \\
Total FM (\%) & $27.6 \pm 10.0$ & $19.4 \pm 7.6$ & $31.0 \pm 8.8$ & $<0.0001^{*}$ \\
Left arm FM (kg) & $28.6 \pm 11.9$ & $20.0 \pm 11.6$ & $32.3 \pm 10.0$ & $<0.0001^{*}$ \\
Right armFM (kg) & $27.4 \pm 10.8$ & $18.5 \pm 6.4$ & $31.2 \pm 10.1$ & $<0.0001^{*}$ \\
Right leg FM (kg) & $30.8 \pm 11.5$ & $17.7 \pm 7.6$ & $36.3 \pm 7.9$ & $<0.0001^{*}$ \\
Left leg FM (kg) & $30.6 \pm 10.9$ & $18.5 \pm 7.6$ & $35.7 \pm 7.6$ & $<0.0001^{*}$ \\
Trunk FM & $25.2 \pm 10.1$ & $20.5 \pm 8.7$ & $27.3 \pm 9.9$ & $<0.0001^{*}$ \\
Total FFM (kg) & $45.8 \pm 10.2$ & $57.3 \pm 9.8$ & $41.0 \pm 5.3$ & $<0.0001^{*}$ \\
Left arm FFM (\%) & $2.4 \pm 0.8$ & $3.2 \pm 0.7$ & $2.0 \pm 0.4$ & $<0.0001^{*}$ \\
Right arm FFM (\%) & $2.4 \pm 0.7$ & $3.2 \pm 0.7$ & $2.0 \pm 0.4$ & $<0.0001^{*}$ \\
Right leg FFM (\%) & $7.8 \pm 1.9$ & $9.9 \pm 1.9$ & $6.9 \pm 1.0$ & $<0.0001^{*}$ \\
Left leg FFM (\%) & $7.6 \pm 1.8$ & $9.7 \pm 1.8$ & $6.8 \pm 0.9$ & $<0.0001^{*}$ \\
Trunk FFM & $25.6 \pm 5.4$ & $31.1 \pm 5.6$ & $23.2 \pm 3.1$ & $<0.0001^{*}$ \\
TBW (\%) & $52.8 \pm 7.5$ & $57.7 \pm 7.2$ & $50.7 \pm 6.6$ & $<0.0001^{*}$ \\
\hline
\end{tabular}

FM: fat mass. FFM: fat-free mass. TBW: total body water.

\footnotetext{
* Data are expressed as mean \pm standard deviation and the $p$ value was calculated by the Student t-test, with $p<0.05$ indicating a statistically significant difference between males and females.
} 


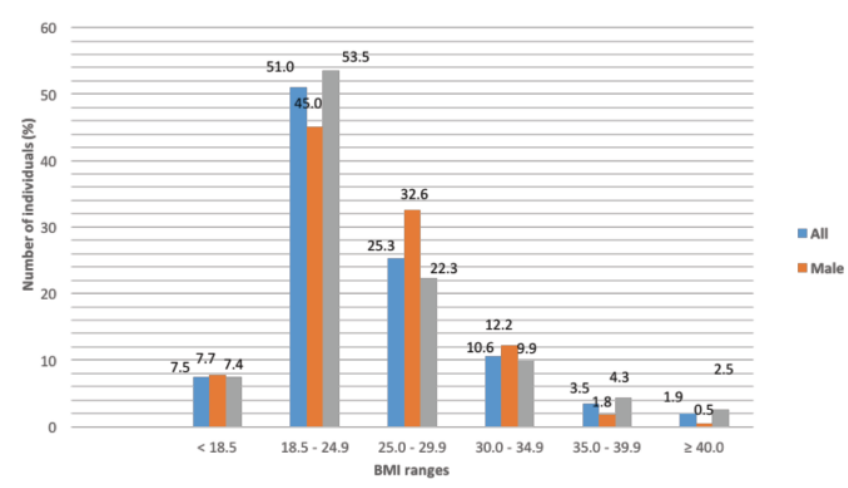

Figure 1: Subject distribution (\%) according to the ranges of classification of nutritional status proposed by the body mass index $\left(\mathrm{kg} / \mathrm{m}^{2}\right)$ and divided by gender.

Table 2: Correspondence between the cutoff points of the BMI $\left(\mathrm{kg} / \mathrm{m}^{2}\right)$ and body fat ranges (\%) according to Gallagher et al (2000).

\begin{tabular}{|c|c|c|c|c|c|}
\hline \multirow[t]{2}{*}{ Fat mass (\%) } & \multicolumn{4}{|c|}{ BMI $\left(\mathrm{kg} / \mathrm{m}^{2}\right)$} & \multirow[t]{2}{*}{ Total } \\
\hline & $<18.5$ & $18.5-24.9$ & $25-29.9$ & $\geq 30.0$ & \\
\hline \multicolumn{6}{|l|}{ Men (\%) } \\
\hline$<8$ & $3.1(12)$ & $4.6(18)$ & $0.5(2)$ & $0(0)$ & $8.3(32)$ \\
\hline $8-20$ & 3.9 (15) & $29.3(113)$ & $11.6(45)$ & $1.8(7)$ & $46.6(180)$ \\
\hline $20-25$ & $0.5(2)$ & $6.7(26)$ & $10.1(39)$ & $2.8(11)$ & $20.2(78)$ \\
\hline$\geq 25$ & $0.3(1)$ & $4.4(17)$ & $10.4(40)$ & $9.8(38)$ & $24.8(96)$ \\
\hline Total & $7.8(30)$ & 45.0 (174) & $32.6(126)$ & $14.5(56)$ & $100(386)$ \\
\hline \multicolumn{6}{|l|}{ Women (\%) } \\
\hline$<21$ & $4.9(45)$ & $7.3(67)$ & $0.1(1)$ & $0(0)$ & $12.3(113)$ \\
\hline $21-33$ & $2.5(23)$ & 39.9 (365) & $5.2(48)$ & $0.7(7)$ & $48.4(443)$ \\
\hline $33-39$ & $0(0)$ & $5.3(49)$ & $10.5(96)$ & $2.8(26)$ & $18.7(171)$ \\
\hline$\geq 39$ & $0(0)$ & $1.0(9)$ & $6.4(59)$ & $13.1(120)$ & $20.5(188)$ \\
\hline Total & $7.4(68)$ & $53.5(490)$ & $22.3(204)$ & $16.7(153)$ & $100(915)$ \\
\hline
\end{tabular}

BMI: body mass index. Results are expressed as percentage and number of individuals.

Table 3: Comparative summary of studies proposing new cutoff points for the BMI for the classification of overweight/obesity in men and women.

\begin{tabular}{ccccc}
\hline Reference & Country & $\mathbf{n}$ & $\begin{array}{c}\text { BMI cutoff points } \\
\text { Men }\left(\mathbf{k g} / \mathbf{m}^{2}\right)\end{array}$ & $\begin{array}{c}\text { BMI cutoff points } \\
\text { Women }\left(\mathbf{k g} / \mathbf{m}^{2}\right)\end{array}$ \\
\hline Deurenberg-Yap et al. (2000) & Singapore & 291 & 26.0 to 27.0 & 26.0 to 27.0 \\
Frankenfield et al. (2001) & US & 141 & 22.6 & 20.1 \\
Ko et al. (2001) & China & 5153 & $23.0-26.0$ & $23.0-26.0$ \\
Dudeja et al. (2001) & India & 123 & 21.5 & 19.0 \\
Oh et al. (2004) & Korea & 773915 & 25.0 & 25.0 \\
Kagawa et al. (2006) & Japan & 139 & - & 23.0 \\
Bozkirli et al. (2007) & Turkey & 909 & 28.24 & 28.02 \\
Romero-Corral et al. (2008) & US & 13601 & 25.8 & 25.5 \\
Laughton et al. (2009) & Canada & 77 & 22.1 & 22.1 \\
Mialich et al. (2011) & Brazil & 200 & $21.84-26.11$ & $22.0-25.3$ \\
Gupta and Kapoor (2012) & India & 578 & $22.9-28.8$ & $22.9-28.8$ \\
Gómez-Ambrozi et al. (2012) & Spain & 6123 & 29.0 & 27.0 \\
Laurson et al. (2011) & US & 8268 & $83^{\text {rd }}$ percentile & $80^{\text {th }}$ percentile \\
Mialich et al. (2014) & Brazil & 501 & 28.38 & 25.24 \\
PRESENT STUDY & Brazil & 1301 & 27.15 & 27.03 \\
\hline
\end{tabular}

\section{Discussion}

Obesity has been routinely described as an epidemic and a significant threat to global health and the use of the BMI takes on a central role in the definition of this excess weight. The BMI has a double function, i.e., it is used both to measure a body attribute (weight in relation to height) and to define a condition (obesity or escess weight).

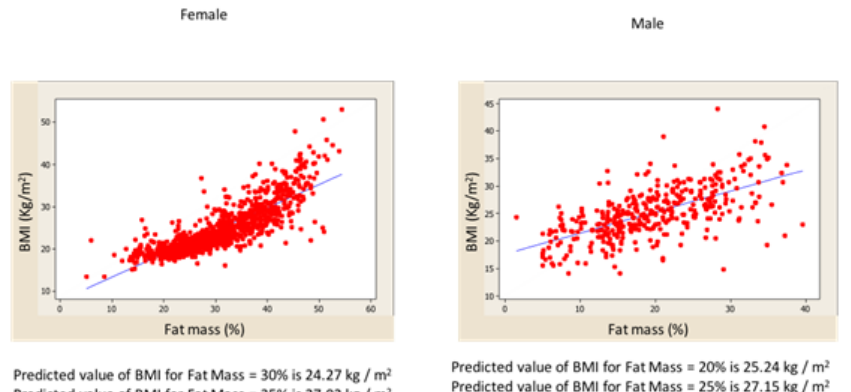

Figure 2: Cut-off point of the traditional BMI for the detection of obesity in men and women of the sample studied, considering percentages of body fat for the classification of overweight and obesity of $20 \%$ and $25 \%$ and $30 \%$ and $35 \%$ for men and women, respectively.

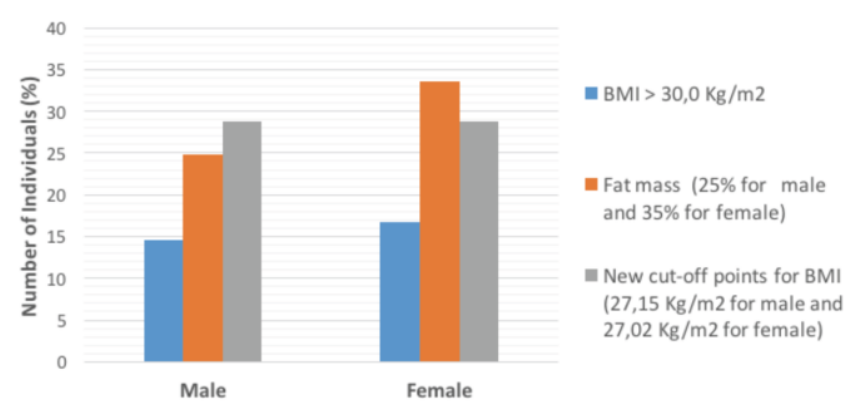

Figure 3: Number of individuals (\%) classified as obese accordig to 3 different criteria: BMI higher than $30 \mathrm{~kg} / \mathrm{m}^{2}$ for men and women, fat mass (\%) higher than 25\% for men and 35\% for women, and new cutoff points for the BMI of $27.15 \mathrm{~kg} / \mathrm{m}^{2}$ for men and $27.02 \mathrm{~kg} / \mathrm{m}^{2}$ for women.

This index, which is calculated using the formula weight/height ${ }^{2}$, was suggested as a new index of excess body weight in 1972 and by the mid-nineties, it became the standard method for both the measurement and definition of obesity.

The subsequent steps involved the definition of its cutoff points, with the proposed values, especially for overweight and obesity, being derived from graphs of mortality rate against BMI. These graphs were often described as having a "J curve" shape, in which a BMI of $30.0 \mathrm{~kg} / \mathrm{m}^{2}$ or $31.0 \mathrm{~kg} / \mathrm{m}^{2}$ marked a point of significant increase of risk when the curve becomes much more accentuated. Even during the 1980's and 1990's, when the BMI was being extensively used, the specific cutoff points used varied among sudies. For example, in 1985 the US National Institutes of Health Conference decided to use a cutoff point for obesity as a BMI of $27.8 \mathrm{~kg} / \mathrm{m}^{2}$ for men and of $27.3 \mathrm{~kg} / \mathrm{m}^{2}$ for women (National Institutes of Health [NIH] Panel on Obesity, 1985), whereas most British investigations used a BMI of $25.0 \mathrm{~kg} / \mathrm{m}^{2}$ for overweight and a BMI of $30.0 \mathrm{~kg} / \mathrm{m}^{2}$ for obesity for both genders.

However, at the end of the 1990 decade, the cutoff points used by the US government were changed. Thus, when the existing cutoff points of the NIH were used, the prevalence of overweight in the adult population was $33.3 \%$ for men and $36.4 \%$ for women, whereas when the 
cutoff points of Bray and Garrow were applied the prevalence became $59.4 \%$ for men and $50.7 \%$ for women. This led to the statement that "By simply changing the overweight cutoffs, the estimated number of overweight adults increases from 61.7 million ( $B M I \geq 27.8$ and 27.3) to 97.1 million (BMI $\geq 25.0$ ), representing a difference of 35.4 million overweight adults. This example calls attention to the actual effect that a shift in BMI criteria can have on determining the population at risk" [18]. At the end of the 1990 's the BMI was sufficiently well established and was defined as a consensus by the WHO in a technical report on anthropometry (WHO, 1995) in which BMI values of 25.0 to $29.9 \mathrm{~kg} / \mathrm{m}^{2}$ were used for overweight and values above 30.0 $\mathrm{kg} / \mathrm{m}^{2}$ were used for obesity. And these have been the cutoff points traditionally used since then in studies using the BMI.

However, the precision of the BMI for the assessment of body fat will continue to be debated since the BMI, although extensively used as a substitute measurement of adiposity, is more a measurement of excess weight in relation to height than a measurement of excess body weight. The BMI does not distinguish between fat mass and fat-free mass nor does it consider the distribution of fat throughout the body. Thus, other measures of adiposity such as waist circumference and waist-hip ratio and information about skinfold thickness and body fat should also be adopted in addition to the BMI.

In this respect, several research groups have discussed the adoption of cutoff points mainly by considering ethnic and body composition differences among world populations and the resuls of these studies are summarized in Table 3. We emphasize the study by Deurenberg-Yap et al. (2000) who investigated the relation between percent body fat and BMI in three different ethnic groups in Singapore (Chinese, Malay and Indians) for a total of 291 subjects and observed that lowering the cutoff point of the BMI for the classification of obesity from $30.0 \mathrm{~kg} / \mathrm{m}^{2}$ to 27.0 $\mathrm{kg} / \mathrm{m}^{2}$ (for Chinese and Malay subjects) and to $26.0 \mathrm{~kg} / \mathrm{m}^{2}$ (for Indian subjects) could increase the prevalence of obesity from $6 \%$ to $16 \%$ in this population, having an important impact on public policies as well as massive economic implications [19].

Frankenfield et al. (2001), in a study of 141 North American individuals (53 men/88 women) using bioelectrical impedance proposed BMI values of $22.6 \mathrm{~kg} / \mathrm{m}^{2}$ for men and $20.1 \mathrm{~kg} / \mathrm{m}^{2}$ for women to determine obesity in that population [20]. In the same year, Ko et al. (2001) analyzed the relation between $\mathrm{BMI}$ and percent body fat obtained by electrical bioimpedance in 5153 Chinese subjects (3734 women and 1419 men) residing in Hong Kong and suggested that BMI values of $23.0 \mathrm{~kg} / \mathrm{m}^{2}$ and 26.0 $\mathrm{kg} / \mathrm{m}^{2}$ would be the most appropriate for the definition of cutoff points for overweight and obesity, respectively, in that population [21]. Dudeja et al. (2001) established appropriate BMI cutoffs for the definition of overweight considering the percentage of fat mass in a healthy Asian Idian population of Northern India [22]. In a study of 123 subjects, on the basis of a ROC curve, the authors proposed that lower BMI values of $21.5 \mathrm{~kg} / \mathrm{m}^{2}$ for men and 19.0 $\mathrm{kg} / \mathrm{m}^{2}$ for women showed optimum sensitivity and specificity and fewer errors in the identification of individuals with a high percentage of body fat.

Oh et al. (2004) studied a cohort of 773,915 Korean men and women aged 30 to 59 years followed up for about 10 years and observed that populations with $\mathrm{BMI} \geq 25.0$ $\mathrm{kg} / \mathrm{m}^{2}$ were increasing rapidly and had a substantial risk for disease. Thus, they suggested that Korea should consider the use of a BMI of $25.0 \mathrm{~kg} / \mathrm{m}^{2}$ as a point for the prevention of obesity and for the control of interventions [23]

Another study conducted on 139 young Japanese women proposed that a BMI value of $23.0 \mathrm{~kg} / \mathrm{m}^{2}$ reflects the current level of fat obtained by DXA better than a BMI of $25.0 \mathrm{~kg} / \mathrm{m}^{2}$ and therefore maximizes the effectiveness of the BMI as a screening tool in this specific population [24].

Bozkirli et al. (2007), based on a sample of 909 adult Turks (249 men and 660 women), proposed BMI values of $28.24 \mathrm{~kg} / \mathrm{m}^{2}$ for men and $28.02 \mathrm{~kg} / \mathrm{mb}^{2}$ for women, thus obtaining an increase from 361 to 457 (a 26.6\% increase) in the number of obese women and an increasee from 79 to 132 (a $67.1 \%$ increase) in the number of obese men when these new cutoff points were used [25].

Romero-Corral et al. (2008), studying a large sample of 13,601 North American individuals of both genders, proposed cutoff BMI values of $25.8 \mathrm{~kg} / \mathrm{m}^{2}$ for men and 25.5 $\mathrm{kg} / \mathrm{m}^{2}$ for women for the classification of obesity [26]. Laughton et al. (2009), in a study of 77 subjects (63 men and 14 women) with spinal cord injury, demonstrated that a cutoff BMI value of $30.0 \mathrm{~kg} / \mathrm{m}^{2}$ failed to identify $73.9 \%$ of the obese participants and that subjects with a spinal cord injury and $\mathrm{BMI} \geq 22.1 \mathrm{~kg} / \mathrm{m}^{2}$ are considered to be at high risk to develop chronic diseases related to obesity [27]

Previous studies by our group have also confirmed this tendency. Mialich et al. (2011), in a study of 100 Brazilian subjects of both genders, detected BMI ranges of 21.84 $26.11 \mathrm{~kg} / \mathrm{m}^{2}$ for men and $22.0-25.3 \mathrm{~kg} / \mathrm{m}^{2}$ for women for the classification of overweight and obesity in this population ${ }^{(13)}$. And in 2014, Mialich et al. (2014) proposed cutoff points of $28.38 \mathrm{~kg} / \mathrm{m}^{2}$ and $25.24 \mathrm{~kg} / \mathrm{m}^{2}$ for a slightly larger sample of the same population [17].

More recent studies continue to raise questions. Gupta and Kapoor (2012) assessed 578 adult subjects (271 men and 307 women ) from Northern India and observed that the best cutoff points for the BMI for overweight and obesity capable of predicting hypertension would be 22.9 $\mathrm{kg} / \mathrm{m}^{2}$ and $28.8 \mathrm{~kg} / \mathrm{m}^{2}$ for men and women, respectively [14]. Gómez-Ambrozi et al. (2012) studied 6123 Caucasians originating from Spain (4208 women and 1915 men) and concuded that the most accurate current cutoff points for 
the diagnosis of obesity in this population were $29.0 \mathrm{~kg} / \mathrm{m}^{2}$ and $27.0 \mathrm{~kg} / \mathrm{m}^{2}$ for men and women, respectively, and that the inclusion of measurements of body composition in routine clinical practice could improve the diagnosis and the decision for the most appropriate treatment of obesity [15].

In the present study, we expected to obtain lower proposed cutoff points for the classical BMI than those traditionally adopted according to the classification ranges proposed by the WHO, i.e., $25.0 \mathrm{~kg} / \mathrm{m}^{2}$ for overweight and above $30.0 \mathrm{~kg} / \mathrm{m}^{2}$ for obesity. On this basis, the results obtained here were $27.15 \mathrm{~kg} / \mathrm{m}^{2}$ for men and $27.02 \mathrm{~kg} / \mathrm{m}^{2}$ for women, in agreement with this worldwide tendency to propose new cutoff poins for the BMI, most of them lower than those currently used and also specific for gender and ethnicity.

Thus, we may conclude that a diagnosis of overweight and obesity based on BMI classification can provide valuable information about the increase in body fat and permit a significant inter- and intrapopulation comparison of body weight. In addition, it can identify persons or groups at risk for morbidity and mortality, thus opening the way for the identification of priorities at the individual or community level and for the assessment of the efficacy of such interventions, especially when its reference points are adjusted to the ethnic and body composition characteristics of the population under study.

\section{Limitations of the study}

For necessity, the present subjcts represented a convenience sample and may not have been representative of the population from which they were recruited. Subjects with acute or chronic diseases that might interfere with the measuring process were excluded. In addition, the objective of the present study was not to provide population ranges according to body fat values, as would be the case for epidemiological studies. Ideally, however, future prospective studies should consider optimized sampling strategies when the formulas for the prediction of of percent body fat are calculated on the basis of the BMI.

A second source of concern is represented by individuals with a BMI of $18.5 \mathrm{~kg} / \mathrm{m}^{2}$ or lower. Only $7.7 \%$ of the males studied here and $7.4 \%$ of the women had a BMI $<18.5 \mathrm{~kg} / \mathrm{m}^{2}$. Thus, the limited number of individuals with low BMI values suggests that very large subject samples are necessary for future studies in order to develop models or that the evaluations of other sbjects involve much leaner populations than those assessed in the present study.

\section{Conclusion}

Thus, the development of the BMI represented an important factor of standardization, which solved concrete problems of investigation and led to the creation of new types of knowledge and new ways of working, consequently facilitating the development of science related to obesity. The adoption of cutoff points for the BMI was crucial for the definition of obesity as an epidemic, permitting the creation of large data banks for the screening of alterations at the population level both regarding mean body weight and a schematic presentation of these changes. These two new entities made it possible for researchers in this area and for others to argue that obesity should be defined as an epidemic.

Finally, we may conclude that, despite the many merits of the BMI, it is also essential to consider that the nutritional profile of the world population has changed considerably from the time when it was developed to the present day, when we are witnessing a significant increase in excess weight/obesity in the population. This justifies the need to propose a refinement of this index, i.e., a reevaluation of its cutoff points so that new classification ranges may be later proposed in order to contemplate a larger number of individuals and to take into account ethnic differences between populations, thus permitting an earlier clinical intervention with a consequent reduction of health care costs. Thus, further studies using appropriate methods are needed in order to fully explore the gamut of questions related to the new classification ranges and/or more appropriate and specific cutoff points for populations that use the BMI as at tool for the assessment of nutritional status.

\section{Conflict of Interest}

The authors declare no conflict of interest.

\section{Acknowledgements}

We would like to acknowledge Fundação de Amparo à Pesquisa do Estado de São Paulo (Fapesp) for partially supporting this research (Protocols: 2012/15944-1 and 2014/18536-7).

\section{References}

1. Abelson P, Kennedy D (2004). The obesity epidemic. Science 304, 1413. 2004

https://doi.org/10.1126/science.304.5676.1413

2. Haslam D, James P. Obesity. Lancet 2005; 366: 1197-1209. https://doi.org/10.1016/S0140-6736(05)67483-1

3. Kelly T, Yang W, Chen CS, Reynolds K, He J. Global burden of obesity in 2005 and projections to 2030. International Journal of Obesity 2008; 32: 1431-1437. https://doi.org/10.1038/ijo.2008.102

4. World Health Organization. Obesity: preventing and managing the global epidemic. Report of a WHO Consultation on Obesity. (WHO technical report series), 1998.

5. Francischi RPP, Pereira LO, Freitas cs, Klopfer M, Santos RC, Vieira P, Lancha Jr AH. Obesity: updated information about its etiology, morbidity and treatment. Rev Nutr 2000; 13:17-28. https://doi.org/10.1590/\$1415-52732000000100003 
6. Associação Brasileira para o Estudo da Obesidade e da Síndrome Metabólica (ABESO). Available at: http://www.abeso.org.br. Accessed: April 1, 2012.

7. Quetelet LAJ. Comparative statistics in the 19th century. Farnborough. United Kingdom: Gregg International Publishers; 1973. A treatise on man and the development of his faculties. Edinburgh. United Kingdom: William and Robert Chambers, 1842.

8. World Health Organization. Physical status: the use and interpretation of anthropometry. Report of a WHO expert committee. (WHO technical report series), 1995.

9. Javed F, Aziz EF, Sabharwal MS, Nadkarni GN, Khan SA, Cordova J et al. Association of BMI and cardiovascular risk stratification in the elderly African American females. Obesity 2010; 19: 1182-6. https://doi.org/10.1038/oby.2010.307

10. Franco LP, Morais CC, Cominetti C. Normal-weight obesity syndrome: diagnosis, prevalence, and clinical implications. Nutr Rev 2016: 1-13. https://doi.org/10.1093/nutrit/nuw019

11. Oliveros $E$, Somers VK, Sochor $\mathrm{O}$ et aL. The concept of normal weight obesity. Progr Cardiovasc Dis 2014: 426-33. https://doi.org/10.1016/j.pcad.2013.10.003

12. Romero-Corral A, Somers VK, Sierra-Johnson J et al. Normal weight obesity: a risk factor for cardiometabolic dysregulation and cardiovascular mortality. Eur Heart J 2010: 737-46. https://doi.org/10.1093/eurheartj/ehp487

13. Mialich MS Martinez EZ, Garcia RWD and Jordao Jr AA. New body mass index adjusted for fat mass (BMIfat) by the use of electrical impedance. Int J Body Comp Res 2011; 9(2): 65-72.

14. Gupta S, Kapoor S. Optimal cut-off values of anthropometric markers to predict hypertension in North Indian population. J Commun Health 2012; 37: 441-7. https://doi.org/10.1007/s10900-011-9461-8

15. Gómez-Ambrosi J, Silva C, Galofre JC, Escalada J, Santos S, Millán D et al. Body mass index classification misses subjects with increased cardiometabolic risk factors related to elevated adiposity. Int J Obesity 2012; 36: 286-294. https://doi.org/10.1038/ijo.2011.100

16. Gallagher D, Heymsfield SB, Heo M, Jebb SS, Murgatriyd PR, Sakamoto $Y$ et al. Healthy percentage body fat ranges: an approach for developing guidelines based on body mass index. Am J Clin Nutr 2000; 72: 694-701. https://doi.org/10.1093/ajen/72.3.694

17. Mialich MS, Martinez EZ, Jordao Jr AA. Application of body mass index adjusted for fat mass (BMIfat) obtained by bioelectrical impedance in adults. Nutr Hosp 2014; 30(2): 417424.
18. Fletcher I. Defining an epidemic: the body mass index in British and US obesity research 1960-2000. Sociol Health Illness 2014; 36 (3): 338-53. https://doi.org/10.1111/1467-9566.12050

19. Deurenberg-Yap M, Schmidt G, Van Staveren WA, Deurenberg $P$. The paradox of low body mass index and high body fat percentage among Chinese, Malays and Indians in Singapore. Int J Obs Relat Metab Disord 2000; 24(8): 1011-7. https://doi.org/10.1038/sj.ijo.0801353

20. Frankenfield DC, Rowe WA, Cooney rn, Smiths JS, Becker D. Limits of body mass index to detect obesity and predict body composition. Nutrition 2001; 17: 26-30. https://doi.org/10.1016/S0899-9007(00)00471-8

21. Ko GT, Tang J, Chan jc, Sung R, Wu MM, Wia HP, Chen R. Lower BMI cut-off value to define obesity in Hong Kong Chinese: an analysis based on body fat assessment by bioelectrical impedance. Br J Nutr 2001; 85(2): 239-42. https://doi.org/10.1079/BJN2000251

22. Dudeja V, Misra A, Pandey RM, Devina G, Kumar G, Vikram NK. $\mathrm{BMI}$ does not accurately predict overweight in Asian Indians in northern India. Br J Nutr 2001; 86; 105-112. https://doi.org/10.1079/BJN2001382

23. Oh SW, Shin S, Yun YH, Yoo T, Huh B. Cut-off point of BMI and obesity-related comorbidities and mortality in middle-aged Koreans. Obesity Research 2004; 12(12): 2031-40. https://doi.org/10.1038/oby.2004.254

24. Kagawa M, Uenishi K, Kuroia C, Mori M, Binns CW. Is the BMI cut off level for Japanese females for obesity set too high? A consideration from a body composition perspective. Asia Pac J Clin Nutr 2006; 15(4): 502-7.

25. Bozkirli E, Ertorer ME, Bakiner O, Tutuncu NB, Demirag NG. The validity of the World Health Organisation's obesity body mass index criteria in a Turkish population: a hospital-based study. Asia Pac J Clin Nutr 2007; 16(3): 443-447.

26. Romero-Corral. A, Somers VK, Sierra-Johnson J, Thomas RJ, Collazo-Clavell ML, Korinek J. et al. Accuracy of body mass index in diagnosing obesity in the adult general population. Int J Obesity 2008: 1-8. https://doi.org/10.1038/ijo.2008.11

27. Laughton GE, Buchholz AC, Martin Ginis KA, Goy RE. Lowering body mass index cutoffs better identifies obese persons with spinal cord injury. Spinal Cord 2009: 7, 1-6. https://doi.org/10.1038/sc.2009.33

28. Laurson KR, Eisenmann JC, Welk GJ. Body Mass Index Standards Based on Agreement with Health-Related Body Fat. Am J Prev Med 2011; 41 (4S2):S100 -S105. 